\title{
ATUAÇÃO DO ASSISTENTE SOCIAL NO CENTRO DE REFERÊNCIA EM ASSISTÊNCIA SOCIAL NOS MUNICÍPIOS DE PEQUENO PORTE I
}

\section{ARTIGO ORIGINAL}

ABEGG, Caroline ${ }^{1}$

ABEGG, Caroline. Atuação do Assistente Social no Centro de Referência em Assistência Social nos Municípios de Pequeno Porte I. Revista Científica Multidisciplinar Núcleo do Conhecimento. Ano 05, Ed. 08, Vol. 05, pp. 15-24. Agosto de 2020. ISSN: 2448-0959, Link de acesso: https://www.nucleodoconhecimento.com.br/ciencias-sociais/atuacao-doassistente

\section{RESUMO}

Esse trabalho é resultado de uma pesquisa de campo realizada no Centro de Referência de Assistência Social no município de Porto Mauá no estado do Rio Grande do Sul. Discorre sobre a atuação do profissional assistente social inserido nesse campo de trabalho de proteção básica em municípios de pequeno porte I. Com o objetivo de analisar os desafios enfrentados, a reafirmação do profissional com as diretrizes profissionais com a efetivação e busca pela garantia de direitos dos usuários através de encaminhamentos para saúde, educação, habitação, atividades de capacitação, geração de emprego, renda e empoderamento da família. Utilizamos como metodologia a revisão bibliográfica. Na pesquisa foi constatado que a falta de investimentos e profissionais necessários para suprir a demanda dos trabalhos existentes.

${ }^{1}$ Pós Graduada Gestão de Pessoas pela Universidade Luterana do Rio Grande do Sul (ULBRA). Pós Graduada Gestão em Serviço Social e Projetos Sociais pela Faculdade Venda Nova do Imigrante (FAVENI). Graduada em Serviço Social Universidade Regional do Noroeste do Estado do Rio Grande do Sul (UNIJUí). 
Palavras-Chave: CRAS, prática profissional, desafios, garantia de direitos.

\section{INTRODUÇÃO}

Quando o profissional Assistente Social é chamado a atuar em municípios de pequeno porte I, muitas vezes não é claro, qual o limite e papel desse profissional no campo o qual está inserido, nem para a equipe, nem para a população usuária desse serviço e muitas vezes nem se quer para o próprio profissional.

Em suas gênesis o Serviço Social teve forte influência da Igreja Católica, fazendo com que muitos ainda atualmente vejam o papel do assistente social como uma evolução da caridade, o que é equivocado.

Busca-se nesse artigo fazer uma reflexão sobre as demandas que chegam a esse profissional e realizar uma análise de qual é seu real papel de atuação do Centro de Referência de Assistência Social (CRAS) em municípios de pequeno porte I, a fim de clarificar e tornar mais efetiva sua atuação.

Através da aproximação com a realidade no CRAS de Porto Mauá pode-se ter mais claro o que ocorre no cotidiano fazendo assim uma reflexão sobre a prática profissional, realizando desse modo um olhar crítico sobre a realidade profissional vivida pelos assistentes sociais inseridos nesse contexto.

Esse trabalho trata-se da percepção do profissional assistente social inserido no campo de trabalho da Política Nacional de Assistência Social (PNAS) no Centro de Referência em Assistência Social no Município de Porto Mauá através de pesquisa de campo realizada 2019 através de atendimentos e visitas domiciliares.

\section{DESENVOLVIMENTO}

Porto Mauá se localiza a noroeste do Estado do Rio Grande do Sul, fronteira com a Argentina. Trata-se de um município de pequeno porte com polução estimada de 2.374 habitantes em 2019. O salário médio dos trabalhadores formais em 2017 era de 2,7 salário mínimos, sendo que apenas $11,6 \%$ da polução possui trabalho formal. $O$ 
Percentual da polução com renda per capita mensal de $1 / 2$ salário mínimo é de $37 \%$, conforme o Instituto Brasileiro de Geografia e Estatística (IBGE).

O Assistente Social é um profissional técnico-operativo que deve atuar levando em consideração os aspecto ético-políticos, teórico metodológicos e técnico operativos da profissão. Exerce uma função de extrema importância dentro do Centro de Referência da Assistência Social (CRAS). Conforme Art. 6o - C da Lei № 12.435, de 6 de julho de:

$\S 1^{\circ}$ O Cras é a unidade pública municipal, de base territorial, localizada em áreas com maiores índices de vulnerabilidade e risco social, destinada à articulação dos serviços socioassistenciais no seu território de abrangência e à prestação de serviços, programas e projetos socioassistenciais de proteção social básica às famílias.

Conforme Braga (2011, p.148) "o CRAS deve prestar serviço, potencializando as mudanças significativas para a população, com vista a mudar suas condições efetivas e torná-las sujeito de sua própria vida".

A demanda atendia pelo CRAS do município de Porto Mauá é das mais variadas, pois o município conta com apenas uma profissional Assistente Social. Enquadra-se como município de pequeno porte I, conforme Art. 6º da Normal Operacional Básica - NOB SUAS (2012):

$\S 3$ ○ Os CRAS serão organizados conforme o número de famílias a ele referenciadas, observando-se a seguinte divisão:

I - até 2.500 famílias;

II - de 2.501 a 3.500 famílias;

III - de 3.501 até 5.000 famílias

Segundo Silva (2015) o número de profissionais que operam nessa área é insuficiente se comparado a demanda do crescimento de trabalhos técnico-burocrático, em que por sua vez consome bastante tempo dos trabalhadores. 
Atendendo assim as demandas da assistência social, educação, saúde e habitação, que atuam nas mais diversas expressões da questão social.

Que de acordo com lamamoto (1999), pode ser definida como um conjunto de expressões da desigualdade de uma sociedade baseada no capitalismo, que tem em comum: cada vez mais o trabalho coletivo na produção social, mesmo que os frutos se mantenham monopolizada por uma parcela da sociedade.

A profissão surgiu em meados de 1930 e teve em sua gênese forte influência da Igreja Católica, tendo um caráter mais doutrinário do que científico, sendo pautado em uma postura moralizante frente as expressões da questão social.

Nessa concepção, considerada como conservadora, o desprezo da estrutura societária, contribui durante muito tempo para o obscurecimento da questão social, "que caracterizou uma cultura profissional acrítica, sem um horizonte utópico que os impulsionasse para o questionamento e às ações consequentes em prol da construção de novos e diferentes rumos em face das diretrizes sociais postas e assumidas pela profissão" (FORTI, 2013, p. 99).

Sendo que por esse motivo, principalmente em municípios menores, esta gênese ainda se faz presente e tem influência na postura de muitos. Enquanto poucos usuários realmente se enxergam como sujeitos de direitos, muitos ainda buscam a postura paternalista da administração pública enquanto outros se quer sentem-se merecedores que qualquer forma de direito, auxílio e orientação.

A identificação da Assistência Social com assistencialismo e filantropia ainda é parte dos desafios a serem enfrentados nesta área. Décadas de clientelismo consolidaram uma cultura tuteladora que não tem favorecido o protagonismo nem a emancipação dos usuários da Assistência Social na nossa sociedade. (YAZBEK, 2004, p. 19)

O em municípios de pequeno porte I o assistente social inserido no CRAS atua na gestão e execução dos serviços ofertados, que de acordo com Silva (2007) se realizam através da gestão e efetuação de projetos sociais, oriundo do desejo de 
mudar algo, através do reconhecimento das necessidades da sociedade, obtidas por diagnósticos sociais.

\subsection{DEMANDAS PRESENTES NO COTIDIANO PROFISSIONAL}

\subsubsection{SERVIÇO DE PROTEÇÃO E ATENDIMENTO INTEGRAL A FAMÍLIA (PAIF)}

O Serviço de Proteção e Atendimento Integral a Família (PAIF) é ofertado de forma continuada no centro de referência e de acordo conforme a Tipificação Nacional de Serviços Socioassistenciais esse tem como finalidade fortalecer a segurança familiar, promover o acesso aos direitos humanos e sociais, e melhor qualidade de vida a estes, prevenir os desvinculo familiares e comunitários, o que acaba proporcionando o protagonismo e autonomia famílias e comunidades (BRASIL, 2009 ).

\subsubsection{SERVIÇO DE CONVIVÊNCIA E FORTALECIMENTO DE VÍNCULOS (SCFV)}

De forma complementar ao PAIF no CRAS é ofertado a crianças e adolescentes de 06 a 18 anos o Serviço de Convivência e Fortalecimento de Vínculos (SCFV) o qual tem caráter preventivo e visa fortalecer as relações familiares e comunitárias, propor a troca de experiências reafirmando esses como sujeitos de direitos.

O SCFV de acordo com a Tipificação Nacional do Serviços Socioassistenciais é um serviço coletivo organizados por equipes, baseando-se em percursos, com objetivo de garantir melhor assistência a seus usuários, a fim de proporcionar um trabalho de socialização com famílias e prevenção a riscos sociais (BRASIL, 2009).

Forma de intervenção social planejada que cria situações desafiadoras, estimula e orienta os usuários na construção e reconstrução de suas histórias e vivências individuais e coletivas, na família e no território. Organiza-se de modo a ampliar trocas culturais e de vivências, desenvolver o sentimento de pertença e de identidade, fortalecer vínculos familiares e incentivar a socialização e a convivência comunitária. Possui caráter preventivo e proativo, pautado na defesa e 
afirmação dos direitos e no desenvolvimento de capacidades e potencialidades, com vistas ao alcance de alternativas emancipatórias para o enfrentamento da vulnerabilidade social (BRASIL, 2009, p.9).

\subsubsection{BENEFÍCIOS EVENTUAIS}

Boa parte dos usuários do CRAS do município não possuem o ensino fundamental completo, sendo relativamente alta a taxa de analfabetos (principalmente idosos). Entre as demandas mais frequentes estão a solicitação de benefícios eventuais principalmente cestas básicas.

Quanto aos benefícios eventuais, de acordo com a PNAS (2004):

Os Benefícios Eventuais, tratados no artigo 22 da LOAS são considerados como provisões gratuitas implementadas em espécie ou em pecúnia, que visam cobrir determinadas necessidades temporárias em razão de contingências, relativas a situações de vulnerabilidades temporárias, em geral relacionadas ao ciclo de vida, a situações de desvantagem pessoal ou a ocorrências de incertezas que representam perdas e danos. Hoje os benefícios eventuais são ofertados em todos os Municípios, em geral com recursos próprios ou da esfera estadual e do Distrito Federal, sendo necessária sua regulamentação mediante definição de critérios e prazos em âmbito nacional.

\subsubsection{HABITAÇÃO}

No CRAS de Porto Mauá há procura de atendimentos em virtude de situações referentes a habitação, pois parte dos usuários residem em casas construídas de forma ilegal e sem documentações das terras, em áreas ribeirinhas de difícil acesso, e grande vulnerabilidade em virtude de enchentes, na barranca do rio Uruguai, com riscos de alagamento. Sendo que outra demanda corriqueira no CRAS é a solicitação de material de construção para auxiliar casas atingidas. Porém sendo essas construídas em locais proibidos, dificulta a atuação do profissional assistente social na garantia desses direitos.

Entretanto Silva (2012) ressalta que, mesmo que algumas vulnerabilidades sejam ocasionadas pela localização territorial, é importante observar que muitos casos de 
vulnerabilidade social dos usuários do serviço da assistência, não estão ligados a este fator, mas sim processos estruturais.

Não observar o contexto é negar a desvinculação da política econômica e social, e a falta e precarização da gestão desses fatores que afetam diretamente toda a sociedade, principalmente os mais necessitados de proteção social.

\subsubsection{GARANTIA DE DIREITOS}

Em muitas localidades não há acesso a telefones ou meios de transporte, sendo que muitos vivem de forma informal, trazendo e vendendo "chibo" (contrabando) da Argentina, realizado com pequenos barcos, na grande maioria das vezes em estado precário. É grande também o número de argentinos que residem de forma ilegal no município, sendo está uma demanda bastante corriqueira no cotidiano profissional da assistência social de Porto Mauá. Como muitos desses não possuem documentação brasileira, e para poder regularizar sua situação precisariam buscar os documentos necessários na sua terra natal e após isso percorrer mais cerca de $95 \mathrm{~km}$ até a cidade de Santo Ângelo para a regularização, muitos optam, por uma questão financeira, permanecer residindo de forma ilegal no Brasil, mais um fator que dificulta o cadastramento das famílias e a garantia de direitos.

Em consonância com o Código de Ética da profissão é dever do assistente social para com os usuários, garantir a sua inclusão no processo da comunicação "sobre as possibilidades e consequências das situações apresentadas", sempre respeitando democraticamente os usuários e suas decisões (CFESS, 2012, s/p).

\subsubsection{PRESTADOR DE SERVIÇO À COMUNIDADE (PSC)}

Atendimento e acompanhamento aos Prestador de Serviço à Comunidade (PSC), trata-se de uma pena restritiva de direito prevista no Código Penal, o objetivo dessa é a ressocialização do apenado à sociedade. 


\subsubsection{MEDIDA SÓCIO EDUCATIVA}

A medida sócio educativa em meio aberto é prevista no Estatuto da Criança e Adolescente (ECA) como, medidas que devem corresponder os períodos do processo de formação do indivíduo, para melhor desenvolvimento da educação básica, sem que este fique prejudicado, evitando efeitos negativos na formação desses indivíduos. Sobre esse fundamento, a execução das medidas reforça a necessidades do investimento na educação para a amplitude de possibilidades à inclusão dos adolescentes, de acordo com suas potencialidades (FERNANDES, 2002).

\subsubsection{OUTRAS DEMANDAS}

Porém o trabalho não se restringe a isso, existe um número ainda maior de demandas que surgem cotidianamente: violência doméstica, acompanhamento de crianças/adolescentes do município abrigados, acompanhamentos de idosos em casas de longa permanência (ambos fora do município, pois o mesmo não conta com esses serviços), solicitações e acompanhamentos vindas do judiciário, saúde, educação, habitação e demais órgãos, públicos ou não.

Segundo lamamoto:

Em primeiro lugar, para garantir uma sintonia do Serviço Social com os tempos atuais, é necessário romper com uma visão endógena, focalista, uma visão "de dentro" do Serviço Social, prisioneiro em seus muros internos. Alargar os horizontes, olhar para mais longe, para o movimento das classes e do Estado em suas relações com a sociedade; não para perder ou diluir as particularidades profissionais, mas, ao contrário, para iluminá-las com maior nitidez. Extrapolar o Serviço Social para melhor apreendê-lo na história da sociedade da qual ele é parte e expressão (IAMAMOTO, 1999, p.20).

A par dessas demandas do próprio serviço social, em município de pequeno porte, muitas vezes acaba sendo solicitado auxílio os quais não seriam de cunho social. Surgindo assim um elevado número de demanda, das mais variadas expressões da questão social. O Assistente Social comprometido com o projeto ético político da 
profissão, deve cuidar para não se tornar um simples burocrata, que reproduz sistematicamente os afazeres do dia a dia.

\section{CONSIDERAÇÕES FINAIS}

É ampla a atuação do profissional assistente social inserido no CRAS, gerando uma série de demandas, as quais muitas vezes assistente social do CRAS sozinho não dá conta das variadas demandas advindas ao seu encontro, fazendo com que acabe "resolvendo" situações de maneira sistêmica. Para tentar amenizar isso é necessário que o profissional seja dinâmico, criativo, propositivo e crítico e busque romper com o paternalismo ainda bastante presente.

Deve-se estar constantemente se aprimorando e em busca de mais conhecimento, fazendo uso das dimensões ético políticas, técnico operativas e teórico metodológica estejam presentes em seu cotidiano, sendo seu norte, mesmo diante da precarização, a fim de buscar a efetivação de direitos dos usuários.

Um dos papeis primordiais do profissional assistente social é garantir direitos para isso é necessário desvelar a realidade social no qual está inseria o usuário, respeitando sempre a liberdade como valor ético central, mas sem se deixar cair no messianismo ou fatalismo.

\section{REFERÊNCIAS}

BRAGA, L. L. C. 0 trabalho de Assistência Social no CRAS. In: O Trabalho do Assistente Social no SUAS: Seminário Nacional/CFESS. Brasília: 2011.

. Ministério do Desenvolvimento Social e Combate à Fome. Tipificação Nacional de Serviços Socioassistênciais. Brasília/DF. MDS 2009.

Presidência da República. Lei Orgânica de Assistência Social, nº. 742, de 7 de setembro de 1993. 
. Presidência da República. Altera a Lei no 8.742, de 7 de dezembro de 1993, que dispõe sobre a organização da Assistência Social. Lei № 12.435, de 6 de Julho de 2011.

. Resolução CNAS no 33 de 12 de dezembro de 2012. Norma Operacional Básica, Brasília/DF. MDS 2012.

. Resolução CNAS no 145, Política Nacional de Assistência Social, de 23 de julho de 2004.

. CFESS. Código de Ética do assistente social e Lei n. 8.662/93. 10. ed. rev. e atual. Brasília: CFESS, 2012.

FERNANDES, M. M. Ação socioeducativa pública. 2. ed. Rio de Janeiro: Lumen Juris, 2002

FORTI, V. Ética, crime e loucura: reflexões sobre a dimensão ética no trabalho profissional. 3 ed. Rio de Janeiro: Lumen Juris, 2013.

IAMAMOTO, M. V. O Serviço Social na contemporaneidade; trabalho e formação profissional. 2. ed. São Paulo: Cortez, 1999.

IBGE - Instituto Brasileiro de Geografia e estatística. Disponível na internet URL: https://cidades.ibge.gov.br/brasil/rs/porto-maua/panorama. Arquivo consultado em 26 de dezembro de 2019.

SILVA, M. G. da. Processos de trabalho e serviço social. In: Interações. Cultura e Comunidade. v. 2 n. 2. P. 35-47. 2007.

SILVA, M. M. Assistência social na realidade municipal: o SUAS e a prevalência do conservadorismo. Revista Katálysis, Florianópolis, v. 18, n. 1, p. 41- 49, jan./jun. 2015. SILVA E SILVA, Maria

SILVA, T. G. M. A vigilância social na política de assistência social: análise dos aspectos conceituais e operacionais no âmbito municipal. Londrina, 2012. 
YAZBEK, M. C. As ambiguidades da assistência social brasileira após dez anos de Loas. Serviço Social \& Sociedade, São Paulo, ano XXV, n. 77, mar. 2004.

Enviado: Agosto, 2020.

Aprovado: Agosto, 2020. 